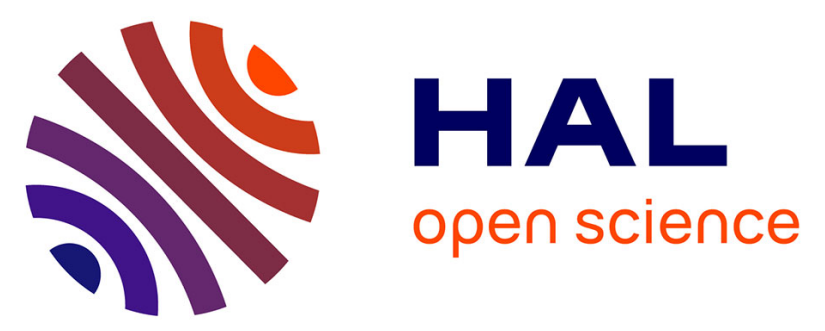

\title{
Stability analysis of homogenized stone column reinforced foundations using a numerical yield design approach
}

M Gueguin, G Hassen, P de Buhan

\section{- To cite this version:}

M Gueguin, G Hassen, P de Buhan. Stability analysis of homogenized stone column reinforced foundations using a numerical yield design approach. Computers and Geotechnics, 2015, 64, pp.10 - 19. 10.1016/j.compgeo.2014.11.001 . hal-01087386

\section{HAL Id: hal-01087386 \\ https://hal-enpc.archives-ouvertes.fr/hal-01087386}

Submitted on 26 Nov 2014

HAL is a multi-disciplinary open access archive for the deposit and dissemination of scientific research documents, whether they are published or not. The documents may come from teaching and research institutions in France or abroad, or from public or private research centers.
L'archive ouverte pluridisciplinaire HAL, est destinée au dépôt et à la diffusion de documents scientifiques de niveau recherche, publiés ou non, émanant des établissements d'enseignement et de recherche français ou étrangers, des laboratoires publics ou privés. 


\title{
Stability analysis of homogenized stone column reinforced foundations using a numerical yield design approach
}

\author{
M. Gueguin*, G. Hassen, P. de Buhan \\ Université Paris-Est, Laboratoire Navier (UMR 8205), CNRS, ENPC, IFSTTAR, 6 et 8 \\ av. B. Pascal, 77455 Marne-La-Vallée, France
}

\begin{abstract}
This paper deals with the ultimate bearing capacity of soft clayey soils, reinforced by stone columns, analyzed in the framework of the yield design theory. Since such geotechnical structures are almost impossible to analyze directly due to the strong heterogeneity of the reinforced soil, an alternative homogenization approach is advocated here. First, numerical lower and upper bound estimates for the macroscopic strength criterion of the stone column reinforced soil are approximated in a rigorous way with convex ellipsoidal sets, which makes the approximated criteria much easier to handle than the initial ones. Then, both static and kinematic approaches are carried out numerically on the homogenized problem using the above approximated macroscopic strength domains in an adapted finite element method. The whole numerical procedure is applied on one classical geotechnical problem: the ultimate bearing capacity of stone column reinforced foundations. The strength capacity of the structure is rigorously framed and the efficiency of the proposed numerical method is highlighted in terms of accuracy and calculation time.
\end{abstract}

Keywords: yield design theory, homogenization approach, stone columns, yield surface approximation, finite element method

\section{Introduction}

Evaluating the ultimate bearing capacity of a soil structure remains a key issue for assessing its performance. One of the most rigorous methods to evaluate this ultimate load is to analyze the structure in the framework of the yield design (or limit analysis) theory $[1,2]$. This method may be seen as an alternative to the iterative methods, such as for example the elastoplastic procedure. Applications

\footnotetext{
* Corresponding author

Email address: maxime.gueguin@enpc.fr (M. Gueguin)
} 
of the yield design theory making use of analytical calculations have been made on several classical geotechnical problems since decades [3-5].

Unfortunately, such analytical tools prove sometimes unable to handle more complex geometries of soil structures. Thus, the use of numerical methods dedicated to the yield design theory has allowed to treat a new kind of geotechnical problems. In this framework, the first applications of the finite element method have been proposed around 40 years ago [6,7], with a linearization of the classical strength criteria. The recent development of powerful numerical tools has brought new opportunities for analyzing numerically three-dimensional geotechnical problems with real strength criteria, such as von Mises and Drucker-Prager $[8,9]$ or Tresca and Mohr-Coulomb [10, 11]. An interested reader would find a comprehensive literature review dedicated to homogeneous geotechnical problems in [12].

It often appears that the ultimate strength capacity of soft clayey soil structures is insufficient to carry design loads. Several techniques have been developed to improve the strength properties of the structure by using inclusions. Among these techniques, the case of "thin" linear inclusions, such as for example metal strips or geotextiles in the earth reinforcement technique or soil nailing, may be directly carried out with finite elements adapted to limit analysis. For such reinforcement techniques, the inclusions are modeled as linear structured elements [13-16].

An other reinforcement technique can be considered, whereby the soft clayey soil is reinforced by large diameter columns. The material used to reinforce the native soil may vary and two subcategories should be distinguished. In the socalled "lime column" reinforcement technique [17], the purely cohesive soil is mixed with a given percentage of lime or lime-cement. The reinforcing material has a much greater cohesion than the native soil, but its friction angle remains relatively small. In the "stone column" reinforcement technique [18], a part of the native soil is replaced by a high frictional material (ballast or gravel). In that case, the reinforcing effect is mostly provided by the friction angle of the reinforcing material, since its cohesion is quite limited.

Referring to the technique of soil improvement by thick columnar frictional inclusions, the volume fraction of the columns (or substitution factor) may range between $10 \%$ and $40 \%$, depending on the kind of reinforcing material. To take the exact geometry of the problem into account, a direct resolution necessitates to model each column in a three-dimensional way. It follows that as soon as a large number of reinforcing columns is involved along with a non uniform loading, and referring for instance to a fem-based calculation procedure, a refined mesh should be used which could lead to an oversized numerical problem and thus considerable computational times.

The present paper advocates the yield design homogenization approach as an alternative to analyze the strength capacities of stone column reinforced soils. After explaining the theoretical difficulties related to the analysis of soft clays reinforced by stone columns, this periodic homogenization method applied to reinforced soils is briefly presented in section 2. The numerical evaluation of the macroscopic strength domain of stone column reinforced soils is then 
performed (section 3). In particular, the necessity to approximate this domain rigorously, for the purpose of analyzing the stability of reinforced soil structures, is highlighted.

Finally, the macroscopic strength domain approximations are employed on the illustrative example of a stone column reinforced foundation, using both static and kinematic approaches of yield design theory. The so-obtained results are favorably compared to other numerical evaluations (section 4).

It should emphasized that the concept of yield design adopted in this paper in place of the more frequently used term of limit analysis, means that constituent materials such as the soil and above all the column material are solely described by means of their strength properties, with no reference to either their elastic properties or any associated plastic flow rule. Detailed arguments on this specific point may be found in [2] about the precise interpretation to be given to the yield design calculations

\section{Periodic homogenization approach as an alternative to direct meth- ods for analyzing reinforced soil structures}

\subsection{A conceptual difficulty in the direct treatment of stone column reinforced soils}

The kinematic approach of the yield design theory is based on the consideration of virtual velocity fields, called failure mechanisms, which allow to determine an upper bound to the strength capacity of the structure. Among such velocity fields, one may consider blocks animated with rigid body motions, separated by velocity discontinuity surfaces. This kind of failure mechanism is often used to address the stability analysis of geotechnical structures, as for example in the "limit equilibrium method" employed to analyze slope stability.

The analysis of stone column reinforced soils based on this particular class of failure mechanisms reveals a fundamental drawback from the yield design point of view $[19,20]$. Indeed, a key ingredient to implementing this approach is the possibility of calculating the maximum resisting work, which in the present case takes the form:

$$
W_{m r}(\underline{U})=\int_{S} \pi(\underline{n},[\underline{U}]) \mathrm{d} S
$$

where $[\underline{U}]$ is the velocity jump across the discontinuity surface $S$ along the unit normal $\underline{n}$ and $\pi$ the corresponding support function. A necessary condition for the stability of the structure is that this maximum resisting work remains greater than or equal to the work developed by the external forces in any velocity field. Depending on the material intersected by the discontinuity surface $S$, the support function $\pi$ takes different expressions [1, 2]:

- The native soil, chosen here as a soft clay with a negligible friction angle, obeys a Tresca criterion with an undrained shear strength $C_{s}$. Thereby, 
the velocity jump must be tangent to the discontinuity surface and corresponds to the following support function:

$$
\pi^{s}(\underline{n},[\underline{U}])= \begin{cases}C_{s}|[\underline{U}]| & \text { if }[\underline{U}] \cdot \underline{n}=0 \\ +\infty & \text { otherwise }\end{cases}
$$

- On the other hand the reinforcing column, considered as a purely frictional material, obeys a Mohr-Coulomb criterion. The possibility of calculating the support function requires that the angle between the discontinuity surface and the velocity jump must be greater than or equal to the friction angle of the column, denoted by $\varphi_{r}$. The corresponding support function is expressed as follows:

$$
\pi^{r}(\underline{n},[\underline{U}])= \begin{cases}0 & \text { if }[\underline{U}] \cdot \underline{n} \geq|[\underline{U}]| \sin \varphi_{r} \\ +\infty & \text { otherwise }\end{cases}
$$

Owing to the three-dimensional geometry of the columns, it turns out that it is impossible to find a failure surface which simultaneously respects these so-called relevance conditions (see Figure 1). Such a "theoretical locking" is nonetheless released if both consituents are purely cohesive, as for lime column reinforced soils. In that case, the friction angle of the reinforcing material being negligible, the velocity jump must be tangential to the discontinuity surface across both constituents.

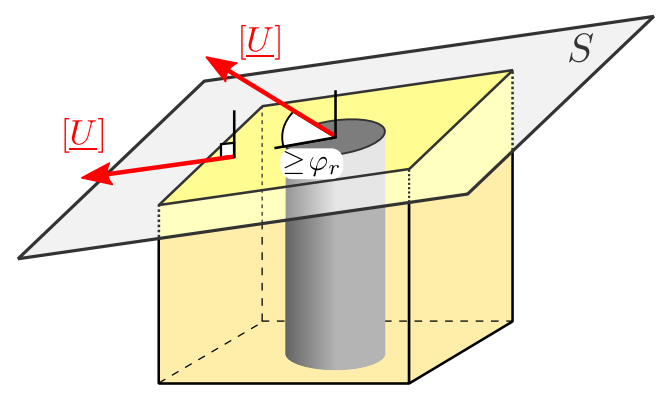

Figure 1: Relevance conditions for a velocity jump across a failure surface intersecting a stone column reinforced soil.

It follows that the traditional analytical methods based on yield design, efficient for homogeneous media, fail to give satisfactory results for the stability analyses of structures made of a purely cohesive native soil reinforced by a highly frictional material (slope stability, ultimate bearing capacity, ...). For this reason, the homogenization approach represents an interesting alternative to treat reinforced soils, which can be seen as composite periodic media.

\subsection{The yield design homogenization approach}

The formulation of the yield design homogenization approach applied to periodic media has been proposed in a general framework [21] and adapted to 
reinforced soils [19]. As for the homogenization method applied to periodic elastic media, the idea is to evaluate the macroscopic mechanical behaviour of the heterogeneous material (its strength domain in the yield design theory) in order to solve the homogenized equivalent problem (see Figure 2).

The assessment of the strength criterion of the homogenized equivalent material is based on the yield design auxiliary problem described on the unit cell, which is the smallest representative volume of reinforced soil. The resolution of this first yield design problem leads to the evaluation of the so-called macroscopic strength domain of the reinforced soil. One of the important results of the yield design homogenization method is that as soon as the characteristic length of the initial problem, denoted here by $B$, is much larger than the characteristic length $L$ of the unit cell $\mathcal{C}$, the resolution of the homogenized equivalent problem provides the same ultimate load than the initial problem.

INITIAL PROBLEM

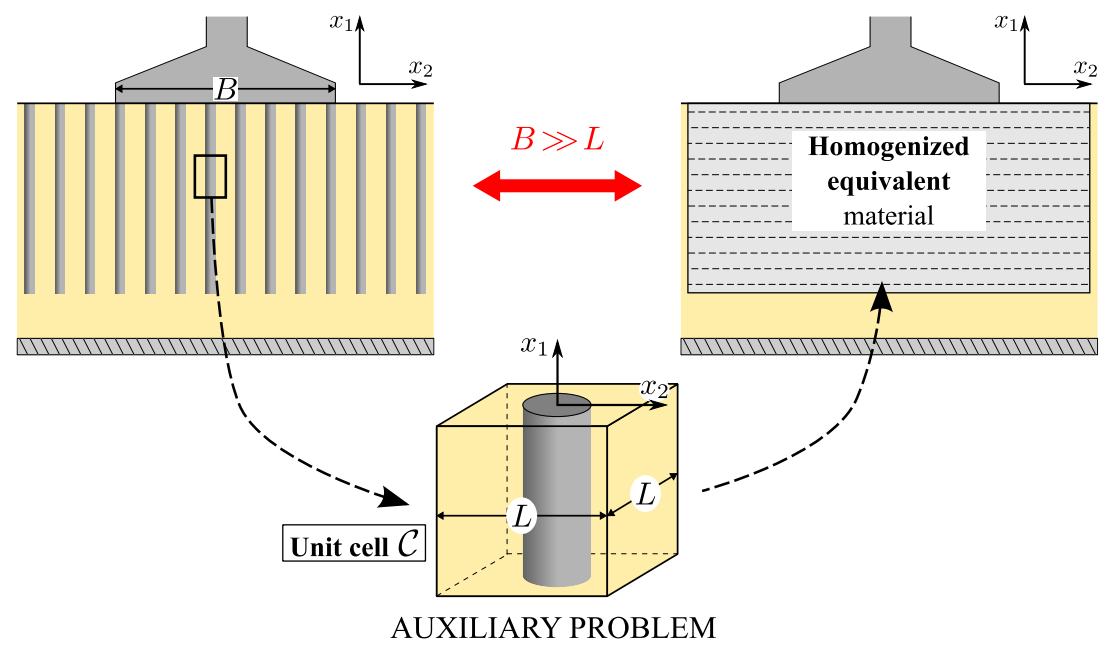

HOMOGENIZED

\section{EQUIVALENT PROBLEM}

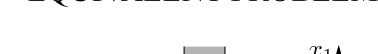

Figure 2: Principle of the periodic homogenization method applied to column reinforced soils.

Within this framework, the macroscopic strength criterion of soils reinforced by "thin" linear inclusions has been evaluated analytically [22, 23] and used to perform the stability analysis of such reinforced soil structures [24, 25]. A comparison has been done between the so-obtained results and a direct analytical approach, which provides justification of the homogenization method [26].

Some authors have evaluated analytically or numerically the macroscopic strength criterion of lime-column reinforced soils (purely cohesive soil reinforced by purely cohesive solumns) by using both kinematic and static approaches of the yield design theory [27-30]. The stability analysis has been performed in such a case for different configurations of structures (embankment resting upon a reinforced soil [31] or ultimate bearing capacity of reinforced foundation under inclined loads [32]). 
On the contrary, due to the aforementioned "theoretical locking", the macroscopic strength criterion of soils reinforced by highly frictional columns has rarely been evaluated analytically [33]. The recent improvement of numerical methods has allowed to get an accurate knowledge of the macroscopic failure behaviour of stone column reinforced soils [20, 34]. But the implementation of such a macroscopic strength domain in order to analyze the stability of homogenized equivalent structures remains so far quite inexistent for such reinforced soils [35].

\subsection{Static and kinematic approaches applied to the auxiliary problem}

The macroscopic strength domain of a periodic heterogeneous medium, denoted by $\mathbf{G}^{\text {hom }}$, is expressed as the set of the macroscopic stresses $\underline{\underline{\Sigma} \text { for which }}$ there exists a stress field $\underline{\underline{\sigma}}$ statically admissible (SA) with $\underline{\underline{\Sigma}}$, verifying the local strength criterion $\mathbf{G}(\underline{x})$ at any point of the unit cell $\mathcal{C}$. $\overline{\bar{T}}$ his domain is then defined as follows:

$$
\mathbf{G}^{h o m}=\{\underline{\underline{\Sigma}} \mid \exists \underline{\underline{\sigma}} \mathrm{SA} \text { with } \underline{\underline{\Sigma}} ; \forall \underline{x} \in \mathcal{C}, \underline{\underline{\sigma}}(\underline{x}) \in \mathbf{G}(\underline{x})\}
$$

which may be explicited as

$$
\underline{\underline{\Sigma}} \in \mathbf{G}^{\text {hom }} \Leftrightarrow \exists \underline{\underline{\sigma}} \text { with } \begin{cases}\operatorname{div} \underline{\underline{\sigma}}(\underline{x})=0 & \text { in } \mathcal{C} \\ {[\underline{\underline{\sigma}}] \cdot \underline{n}=\underline{0}} & \text { across } S_{\text {disc }} \\ \underline{\underline{\sigma}} \cdot \underline{\underline{n}} \text { anti-periodic } & \text { on the boundary of } \mathcal{C} \\ \langle\underline{\underline{\sigma}}\rangle=\frac{1}{|\mathcal{C}|} \int_{\mathcal{C}} \underline{\underline{\sigma}} \mathrm{d} \mathcal{C}=\underline{\underline{\Sigma}} & \\ f(\underline{\underline{\sigma}}(\underline{x})) \leq 0 & \forall \underline{x} \in \mathcal{C}\end{cases}
$$

where the first four equations refer to the static admissibility in the context of periodicity (see [20] for more details). The respect of the local strength criterion is expressed by the last condition.

As mentioned previously, the native soil obeys a Tresca criterion, depending on its undrained shear strength $C_{s}$, whereas the columnar inclusion is represented by a Mohr-Coulomb material, with no cohesion and a friction angle $\varphi_{r}$. Hence, the local strength criterion of the stone column reinforced soil is defined by:

$$
f(\underline{\underline{\sigma}}(\underline{x}))= \begin{cases}\sigma_{M}-\sigma_{m}-2 C_{s} & \text { in the native soil } \\ \sigma_{M}\left(1+\sin \varphi_{r}\right)-\sigma_{m}\left(1-\sin \varphi_{r}\right) & \text { in the column }\end{cases}
$$

$\sigma_{M}$ and $\sigma_{m}$ denoting the major and the minor principal stresses of $\underline{\underline{\sigma}}$ respectively.

The static and kinematic approaches of the yield design theory may be performed on this auxiliary problem in order to produce lower and upper bound estimates for the macroscopic strength domain. 


\subsubsection{Lower bound static approach}

The derivation of a lower bound estimate for $\mathbf{G}^{\text {hom }}$ comes directly from definition (5). It consists in considering trial stress fields $\underline{\underline{\sigma}}$. statically admissible with macroscopic stresses $\underline{\underline{\Sigma}}_{i}$ and complying with the strength criterion in both constituents of the reinforced soil. The lower bound estimate $\mathbf{G}^{\mathrm{lb}}$ is then constructed as the convex envelope of the set of $\underline{\underline{\Sigma}}_{i}$ (see Figure 3).

\subsubsection{Upper bound kinematic approach}

An upper bound estimate for $\mathbf{G}^{\text {hom }}$ is obtained by considering velocity fields $\underline{U}$, kinematically admissible (KA) with a macroscopic strain rate $\underline{\underline{D}}$ and providing an upper bound for the macroscopic support function:

$$
\sup \left\{\underline{\underline{\Sigma}}: \underline{\underline{D}} \mid \underline{\underline{\Sigma}} \in \mathbf{G}^{h o m}\right\}=\pi^{h o m}(\underline{\underline{D}}) \leq \pi^{\mathrm{ub}}(\underline{\underline{D}})=\langle\pi(\underline{\underline{d}})\rangle=\frac{1}{|\mathcal{C}|} \int_{\mathcal{C}} \pi(\underline{\underline{d}}) \mathrm{d} \mathcal{C}
$$

The local support function is expressed, for the purely cohesive native soil, by:

$$
\pi^{s}(\underline{\underline{d}})= \begin{cases}C_{s}\left(\left|d_{\mathrm{I}}\right|+\left|d_{\mathrm{II}}\right|+\left|d_{\mathrm{III}}\right|\right) & \text { if } \operatorname{tr} \underline{\underline{d}}=0 \\ +\infty & \text { otherwise }\end{cases}
$$

and, for the purely frictional column, by:

$$
\pi^{r}(\underline{\underline{d}})= \begin{cases}0 & \text { if } \operatorname{tr} \underline{\underline{d}} \geq \sin \varphi_{r}\left(\left|d_{\mathrm{I}}\right|+\left|d_{\mathrm{II}}\right|+\left|d_{\mathrm{III}}\right|\right) \\ +\infty & \text { otherwise }\end{cases}
$$

where $d_{\mathrm{I}}, d_{\mathrm{II}}$ and $d_{\mathrm{III}}$ are the eigenvalues of the strain rate tensor $\underline{d}$.

As for the static approach, this optimization of the velocity field can be carried out for a series of macroscopic strain rate directions. The set $\mathbf{G}^{\mathbf{u b}}$, the boundary of which is defined by multiple planes depending on $\pi^{\mathrm{ub}}$ in the stress space (see Figure 3), is then an upper bound estimate for the macroscopic strength domain.

$$
\mathbf{G}^{h o m} \subseteq \mathbf{G}^{\mathrm{ub}}=\bigcap_{\underline{\underline{D}}}\left\{\underline{\underline{\underline{\Sigma}}} \mid \underline{\underline{\underline{\Sigma}}}: \underline{\underline{D}} \leq \pi^{\mathrm{ub}}(\underline{\underline{D}})\right\}
$$

\section{Macroscopic strength domain of soils reinforced by stone columns}

\subsection{Evaluation of bounds for the macroscopic strength domain}

The implementation of the static (resp. kinematic) approach, which leads to a maximization (resp. minimization) problem, may be performed numerically. For materials obeying Tresca or Mohr-Coulomb criteria, these problems involve the use of semidefinite programming. A detailed explanation of the numerical implementation of these approaches into the finite element method dedicated to yield design is given in [34]. 


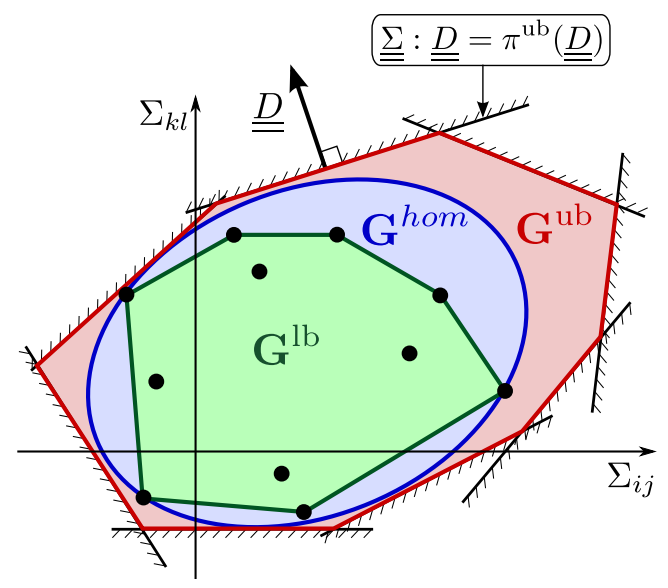

Figure 3: Definition of lower bound and upper bound estimates for a macroscopic strength domain.

Both approaches of the yield design theory are carried out on the auxiliary problem associated to the stone column reinforced soil. The geometrical and mechanical characteristics are chosen as follows:

$$
\eta=0.28 \text { and } \varphi_{r}=35^{\circ}
$$

where $\eta$ denotes the volume fraction of the reinforcing material.

The homogenized equivalent problem to be analyzed may be treated as a plane strain problem in the $\left(x_{1}, x_{2}\right)$-plane, where $x_{1}$ and $x_{2}$ denote the reinforcement direction and a horizontal direction respectively (see Figure 2). Under such conditions, the macroscopic "plane strain" strength criterion $\mathbf{G}^{\text {hom }}$, as well as the lower and upper bound estimates $\mathbf{G}^{\mathrm{lb}}$ and $\mathbf{G}^{\mathrm{ub}}$, may be drawn in the $\left(\Sigma_{11}, \Sigma_{22}, \Sigma_{12}\right)$-space. The efficiency of the assessment of $\mathbf{G}^{\mathrm{lb}}$ and $\mathbf{G}^{\mathrm{ub}}$ for such reinforced soils has been thoroughly discussed in [34]. Here, with reasonable calculation times, the relative gap between the numerical lower and upper bound estimates varies between $0.2 \%$ and $8.5 \%$, with an average value equal to $3.2 \%$.

The so-obtained numerical lower bound estimate $\mathbf{G}^{\mathrm{lb}}$ is represented in Figure 4 in the space of non-dimensional stresses $\left(\Sigma_{11} / C_{s}, \Sigma_{22} / C_{s}, \Sigma_{12} / C_{s}\right)$. It is an unbounded strength domain, which means that for many macroscopic strain rate directions $\underline{\underline{D}}$, its support function takes infinite values. This specific feature derives directly from the strength criterion of the constitutive materials [33]. For both domains $\mathbf{G}^{\mathrm{lb}}$ and $\mathbf{G}^{\mathrm{ub}}$, the set of macroscopic strain rate directions generating a limit load is a cone. These two cones, denoted by $\{\underline{\underline{D}}\}^{\mathrm{lb}}$ and $\{\underline{\underline{D}}\}^{\mathrm{ub}}$ respectively, may be seen as the cones of outer normals to the strength domains, also called "relevance cones".

A second remark concerns the numerical yield surfaces obtained here. For the assessment of $\mathbf{G}^{\mathrm{lb}}$ and $\mathbf{G}^{\mathrm{ub}}$, the space of macroscopic stresses has been explored with a discretization of one degree. As a result, the two strength domains are 


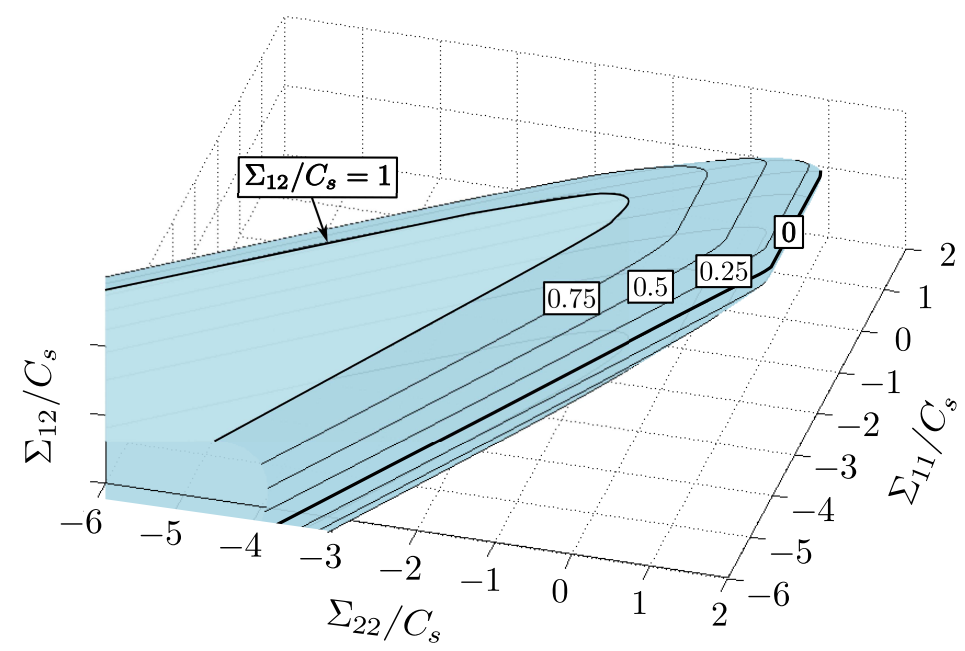

Figure 4: Lower bound to the macroscopic strength domain of a stone column reinforced soil.

polyhedra, defined by more than 16000 planes in the $\left(\Sigma_{11} / C_{s}, \Sigma_{22} / C_{s}, \Sigma_{12} / C_{s}\right)$ space. Consequently, the direct use of such strength domains in a structural stability analysis (in the framework of the finite element method) appears to be quite unrealistic. Indeed, it would mean that these 16000 linear constraints, associated to $\mathbf{G}^{\mathrm{lb}}$ or $\mathbf{G}^{\mathrm{ub}}$, should be verified at each evaluation point of the discretized homogenized structure, leading to an oversized optimization problem.

\subsection{Principle of strength domain's approximations using convex ellipsoidal sets}

The latter remark suggests the necessity to find an alternative method for using the numerical lower and upper bound estimates for $\mathbf{G}^{\text {hom }}$ in stability analyses of reinforced soil structures. The idea is to approximate in a rigorous way both macroscopic strength domains with the minimum number of variables.

Denoting by $\mathbf{G}_{\mathrm{app}}^{\mathrm{lb}}$ the lower bound approximation to $\mathbf{G}^{\mathrm{lb}}$ and by $\mathbf{G}_{\mathrm{app}}^{\mathrm{ub}}$ the upper bound approximation to $\mathbf{G}^{\mathrm{ub}}$, the following set of inclusions holds true:

$$
\mathbf{G}_{\text {app }}^{\mathrm{lb}} \subseteq \mathbf{G}^{\mathrm{lb}} \subseteq \mathbf{G}^{\mathrm{hom}} \subseteq \mathbf{G}^{\mathrm{ub}} \subseteq \mathbf{G}_{\mathrm{app}}^{\mathrm{ub}}
$$

Referring to bounded strength domains, some authors have quite recently proposed to use the sum of convex ellipsoidal sets to approximate these domains [36]. More details concerning the mathematical aspects of the numerical approximation procedure are given in Appendix A. The inclusion relation (12) is sketched in Figure 5, taking into account the difference between the relevance cone of each domain.

\subsection{Results of the numerical approximations}

The numerical procedure has been carried out to approximate $\mathbf{G}^{\mathrm{lb}}$ and $\mathbf{G}^{\mathrm{ub}}$ by a sum of 7 ellipsoidal sets (i.e. 45 parameters). Cross-sections of the yield 


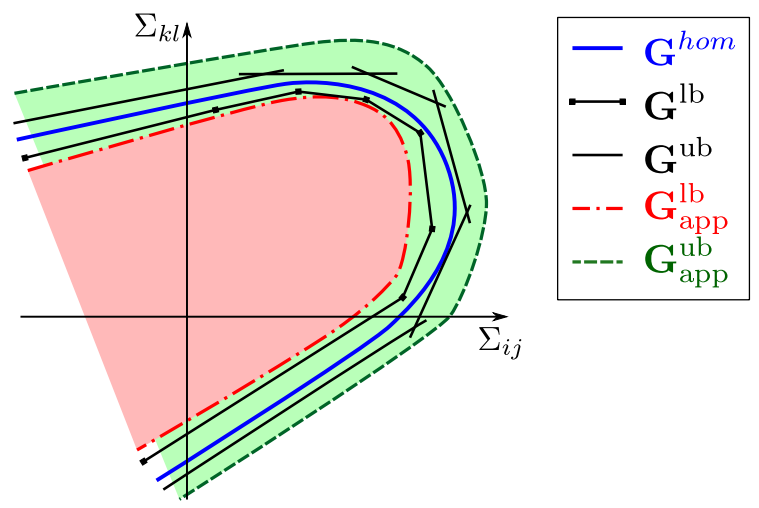

Figure 5: Representation of different estimates for an unbounded macroscopic strength domain in the macroscopic stress space.

surfaces corresponding to both approximated domains by planes of constant shear stress $\left(\Sigma_{12} / C_{s}=\right.$ cst. $)$ are displayed in Figure 6 .

For $\Sigma_{12} / C_{s}=0$, the criteria of the native soil and the stone column material are represented. It is worth noting that the strength properties of the reinforced soil are improved as compared to those of the native soil in the region of compressive stresses, but weaker for tensile stresses.

The relative gap between $\mathbf{G}_{\mathrm{app}}^{\mathrm{lb}}$ and $\mathbf{G}_{\mathrm{app}}^{\mathrm{ub}}$, calculated by means of their support functions, is represented in Figure 7, depending on the angles $\beta$ and $\delta$ defining the orientation of $\underline{\underline{D}}$ in the macroscopic strain rates space $\left(D_{11}, D_{22}, 2 D_{12}\right)$ (see Figure 7). This relative gap may be defined only on the relevance cone of $\mathbf{G}_{\text {app }}^{\mathrm{ub}}$, since $\pi_{\mathrm{app}}^{\mathrm{ub}}$ is infinite for all $\underline{\underline{D}}$ not included in $\{\underline{\underline{D}}\}_{\mathrm{app}}^{\mathrm{ub}}$.

This relative gap varies between $1.2 \%$ and $15.8 \%$, with an average value calculated over all the strain rate orientations equal to $8.2 \%$. It confirms the accuracy of the approximation method and the quality of the so-obtained approximated domains, which can now be implemented for treating homogenized equivalent problems.

\section{Computing the ultimate bearing capacity of a stone column rein- forced foundation}

\subsection{Problem statement}

The aim of this section is now to analyze the stability of a reinforced soil foundation using the yield design homogenization approach. The problem under consideration is that of a rigid strip footing of width $B$ lying on a stone column reinforced soil (see Figure 8). A load of linear density $Q$, inclined at an angle $\alpha$ to the vertical direction $\underline{e}_{1}$, is applied along the strip footing's axis $O x_{3}$. Moreover, the structure is subjected to the gravity via the specific weight $\gamma$ of the constitutive materials, which is taken equal for the soil and the stone column. 


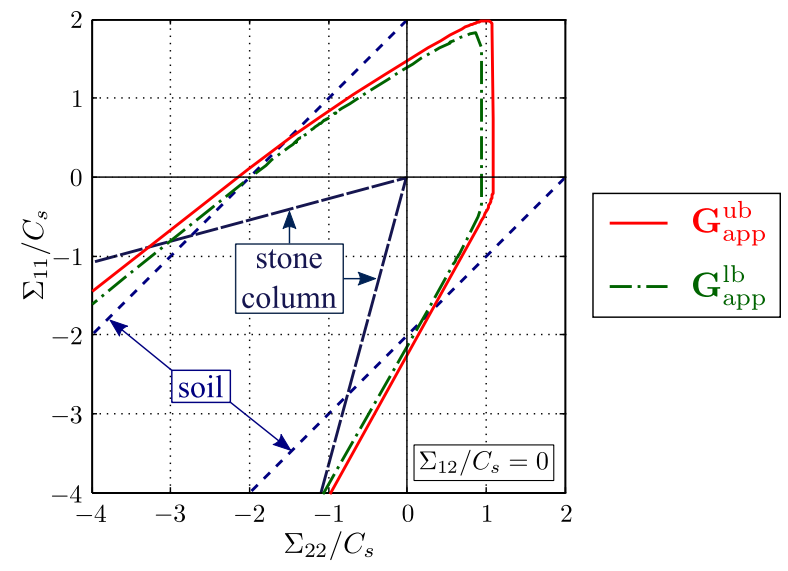

(a)

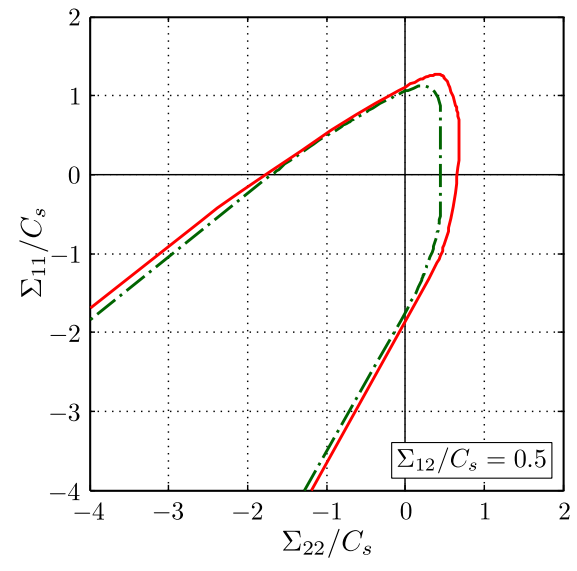

(b)

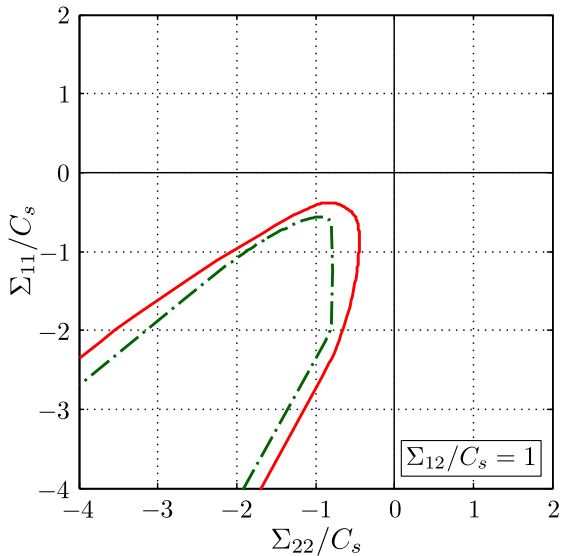

(c)

Figure 6: Cross-sectional views of the approximated bound estimates for the macroscopic strength domain of a stone column reinforced soil.

According to the yield design homogenization method, the zone of the foundation occupied by the reinforced soil is replaced by a homogeneous material which obeys the anisotropic macroscopic strength criterion. The length of the footing is supposed to be infinite along the horizontal direction $\underline{e}_{3}$ and the purely cohesive native soil is considered to be infinitely reinforced along that same direction. As a consequence of these assumptions, the homogenized equivalent problem can be treated as a two dimensional plane strain problem in the $\left(x_{1}, x_{2}\right)$-plane.

The height and the width of the reinforcing zone are denoted by $H$ and $W$, while $B_{0}$ represents the width of the ground under consideration. Fixed boundary conditions are imposed along the lateral and lower sides of the homogenized 


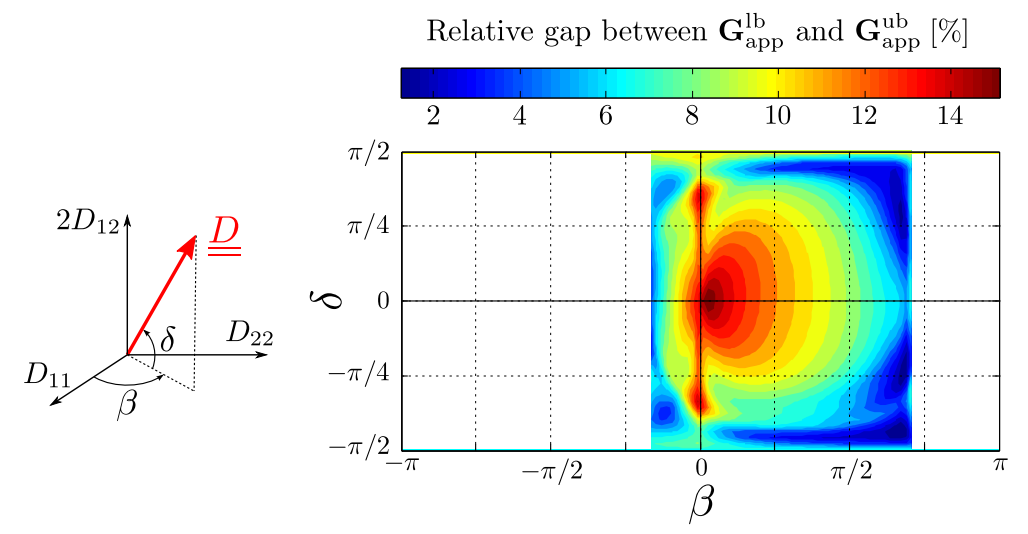

Figure 7: Relative gap between the approximated domains depending on the strain rate orientation.
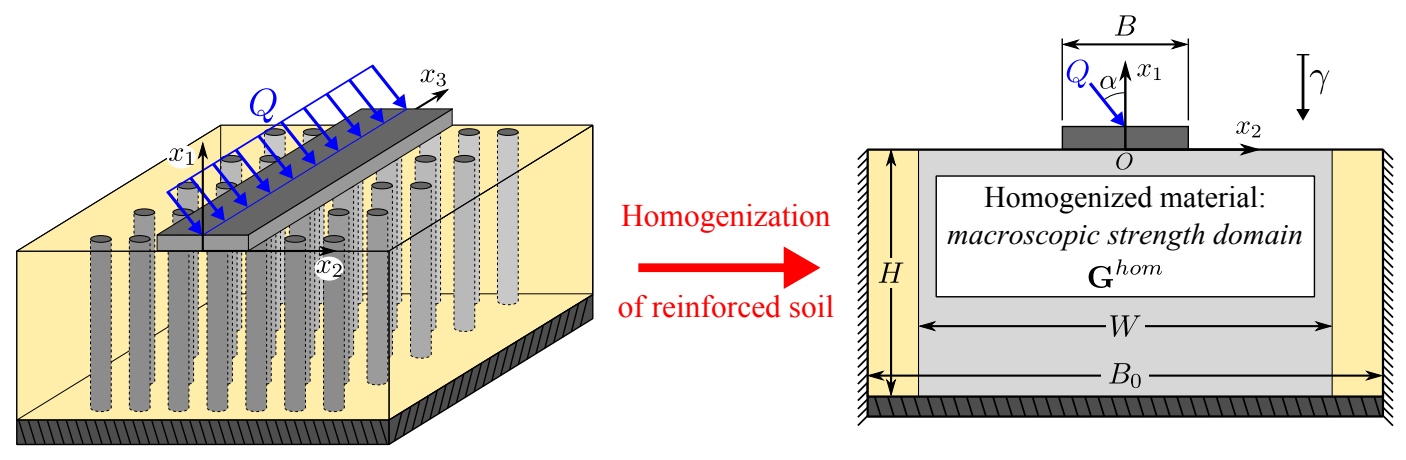

Figure 8: Yield design homogenization method applied to the stability analysis of a stone column reinforced foundation.

problem, giving the following conditions for the velocity field $\underline{U}$ :

$$
\begin{gathered}
\underline{U}\left(x_{1}=-H,-B_{0} / 2 \leq x_{2} \leq B_{0} / 2\right)=\underline{0} \\
\underline{U}\left(-H \leq x_{1} \leq 0, x_{2}= \pm B_{0} / 2\right)=\underline{0}
\end{gathered}
$$

Meanwhile, the upper surface located outside the strip footing is stress free $\left(\underline{T}\left(x_{1}=0,\left|x_{2}\right|>B / 2\right)=\underline{0}\right)$ and perfect bonding is assumed at the footingfoundation interface.

Expressing the global equilibrium of the strip footing in terms of resultant 
and moment gives:

$$
\begin{gathered}
Q \cos \alpha=-\int_{-B / 2}^{B / 2} \sigma_{11} \mathrm{~d} x_{2} \\
Q \sin \alpha=\int_{-B / 2}^{B / 2} \sigma_{12} \mathrm{~d} x_{2} \\
\int_{-B / 2}^{B / 2}-x_{2} \sigma_{11} \mathrm{~d} x_{2}=0
\end{gathered}
$$

Numerical static and kinematic approaches will be carried out on the homogenized problem. For the kinematic approach, the considered velocity fields must respect the following boundary condition:

$$
\underline{U}\left(x_{1}=0,-B / 2 \leq x_{2} \leq B / 2\right)=\left(\dot{\delta_{1}}-\dot{\omega} x_{2}\right) \underline{e}_{1}+\dot{\delta}_{2} \underline{e}_{2}
$$

where $\dot{\delta}_{1}$ and $\dot{\delta}_{2}$ denote the horizontal and vertical velocity at point $O$ of the footing and $\dot{\omega}$ its angular velocity about the $O x_{3}$-axis.

\subsection{Implementation of the numerical static and kinematic approaches}

\subsubsection{Lower bound static approach}

By definition, the static approach leads to a lower bound estimate $Q^{\mathrm{lb}}$ for the ultimate bearing capacity $Q^{+}$defined as

$$
Q^{+}=\sup \left\{\begin{array}{l|l}
Q & \begin{array}{l}
\exists \underline{\sigma} \mathrm{SA} \text { with } Q\left(-\cos \alpha \underline{e}_{1}+\sin \alpha \underline{e}_{2}\right) \\
\forall \underline{x} \in \Omega, \underline{\sigma}(\underline{x}) \in \mathbf{G}^{h o m}
\end{array}
\end{array}\right\}
$$

The numerical lower bound static approach is implemented by discretizing the structure into three-noded triangular stress elements in the $\left(x_{1}, x_{2}\right)$-plane. Each element is associated with its own set of internal stress evaluation points and the nodal stress components are interpolated with linear shape functions (see [37] for more details).

If we had access to the exact macroscopic strength domain $\mathbf{G}^{\text {hom }}$, performing such a numerical static approach would lead to a lower bound estimate $Q^{\mathrm{lb}}\left(\mathbf{G}^{\text {hom }}\right)$ for the ultimate bearing capacity of the reinforced soil. The discretization of the structure into finite elements would imply a gap between $Q^{+}$ and $Q^{\mathrm{lb}}\left(\mathbf{G}^{\text {hom }}\right)$.

Thanks to its status, the use of the numerical lower bound $\mathbf{G}^{\mathrm{lb}}$ would obviously lead to an other lower bound estimate for $Q^{+}$, smaller than the previous one. Unfortunately, for the reasons underlined previously, $\mathbf{G}^{\mathrm{lb}}$ cannot be directly implemented in the homogenized structural problem, but must be approximated by $\mathbf{G}_{\mathrm{app}}^{\mathrm{lb}}$. One finally gets the following sequence of inequalities

$$
Q^{+} \geq Q^{\mathrm{lb}}\left(\mathbf{G}^{h o m}\right) \geq Q^{\mathrm{lb}}\left(\mathbf{G}^{\mathrm{lb}}\right) \geq Q^{\mathrm{lb}}\left(\mathbf{G}_{\mathrm{app}}^{\mathrm{lb}}\right)
$$

so that the gap between the exact ultimate bearing capacity $Q^{+}$and its sole computable lower bound estimate $Q^{\mathrm{lb}}\left(\mathbf{G}_{\mathrm{app}}^{\mathrm{lb}}\right)$ is the result of the sum of the gaps induced by each succesive approximation. 


\subsubsection{Upper bound kinematic approach}

Similarly an upper bound estimate for the ultimate bearing capacity $Q^{+}$ will be derived from the kinematic approach of the yield design theory. For the purpose, the reinforced soil structure is discretized into six-noded triangular elements in the $\left(x_{1}, x_{2}\right)$-plane. This means that the velocity fields involved will vary quadratically on each such element, the velocity being continuous between adjacent elements (see [38] for more details).

In the same way as for the static approach, different macroscopic strength domains may be used in order to produce upper bounds for $Q^{+}$. For the same reasons than those exposed previously, $\mathbf{G}^{\text {hom }}$ and $\mathbf{G}^{\mathrm{ub}}$ cannot be implemented in a numerical kinematic approach. The only treatable upper bound estimate for the ultimate bearing capacity is performed by using the approximated domain $\mathbf{G}_{\mathrm{app}}^{\mathrm{ub}}$, which is an evaluation by outside of $\mathbf{G}^{\text {hom }}$. Hence the following inequalities

$$
Q^{+} \leq Q^{\mathrm{ub}}\left(\mathbf{G}^{h o m}\right) \leq Q^{\mathrm{ub}}\left(\mathbf{G}^{\mathrm{ub}}\right) \leq Q^{\mathrm{ub}}\left(\mathbf{G}_{\mathrm{app}}^{\mathrm{ub}}\right)
$$

The gap between the so-obtained upper bound estimate $Q^{\mathrm{ub}}\left(\mathbf{G}_{\mathrm{app}}^{\mathrm{ub}}\right)$ and $Q^{+}$ is due to the numerical discretization of the structural problem, the use of numerical method for evaluating $\mathbf{G}^{\mathrm{ub}}$ as well as the precision of its numerical approximation $\mathbf{G}_{\text {app }}^{\mathrm{ub}}$ by a sum of ellipsoids.

\subsubsection{Remarks on the numerical implementation}

Figure 9 depicts the steps of the numerical homogenization method proposed in this article. As shown in this flow chart, the evaluation of $Q^{\mathrm{lb}}\left(\mathbf{G}_{\mathrm{app}}^{\mathrm{lb}}\right)$ and $Q^{\mathrm{ub}}\left(\mathbf{G}_{\mathrm{app}}^{\mathrm{ub}}\right)$ are the final goal of the present method.

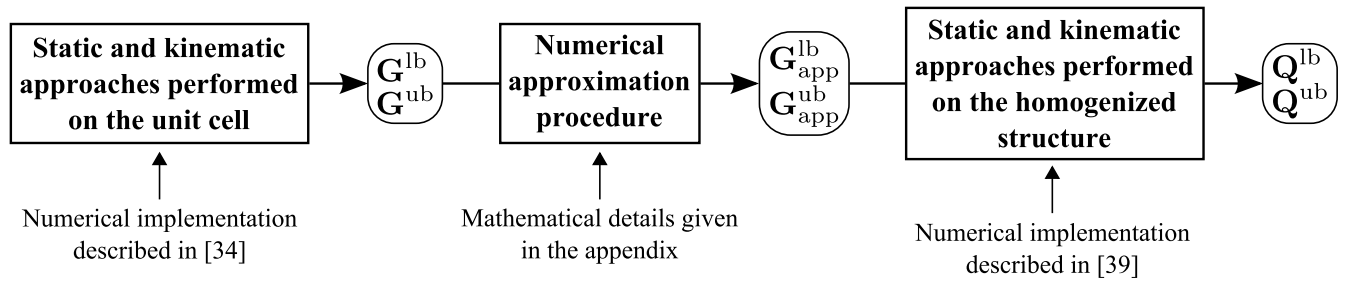

Figure 9: Description of the steps of the numerical homogenization method.

The maximization and minimization problems, associated to the static and kinematic approaches respectively, may be implemented numerically by considering the discretized stress and velocity fields. With the definition of the approximated domains $\mathbf{G}_{\mathrm{app}}^{\mathrm{lb}}$ and $\mathbf{G}_{\mathrm{app}}^{\mathrm{ub}}$ as sum of ellipsoids, it is worth noting that the numerical static and kinematic approaches may be formulated as optimization problems subject to a set of linear and second-order conic constraints. An interested reader would find all the details of these formulations in the appendix of [39].

The numerical static and kinematic approaches have been performed on a DELL PC (Intel-P4 2.4GHz) running Linux 32-bits using MOSEK [40] in the 
MATLAB (2010a) environment. The optimizer allows, among others, to treat this kind of problems using second-order cone programming (SOCP). These approaches will be now used on the illustrative example and the relative gap between the final bounds $Q^{\mathrm{lb}}\left(\mathbf{G}_{\mathrm{app}}^{\mathrm{ub}}\right)$ and $Q^{\mathrm{ub}}\left(\mathbf{G}_{\mathrm{app}}^{\mathrm{ub}}\right)$, which characterizes the accuracy of the whole numerical homogenization method proposed in that paper, will be evaluated.

\subsection{Presentation of results}

For the upcoming computations, the following geometrical characteristics of the problem have been selected

$$
H=25 \mathrm{~m}, W=20 \mathrm{~m}, B_{0}=45 \mathrm{~m} \text { and } B=10 \mathrm{~m}
$$

and the specific weight $\gamma$ of the homogenized material taken equal to $18 \mathrm{kN} / \mathrm{m}^{3}$. The inclination angle $\alpha$ takes discrete values with an increment of $1^{\circ}$.

The mesh adopted to discretize the structure will be the same for the static and kinematic approaches, as represented in Figure 10 (2016 elements and 4135 nodes for the kinematic approach).

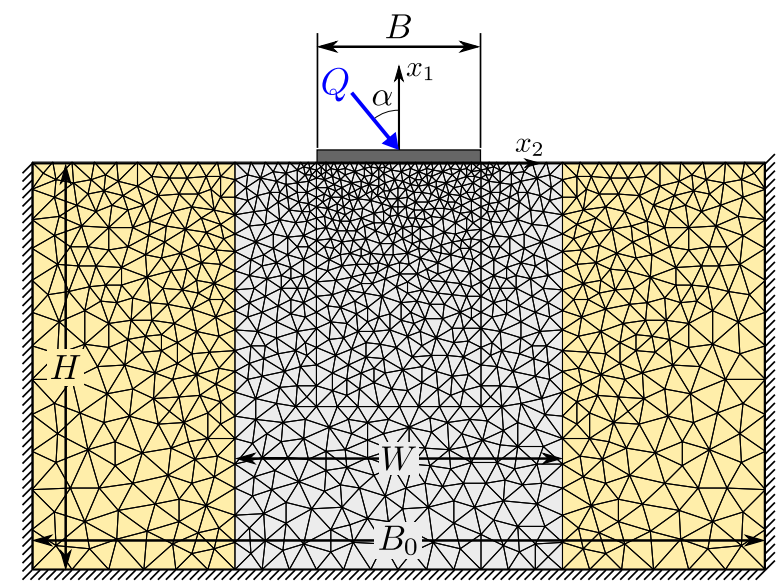

Figure 10: Finite element mesh adopted for obtaining the numerical lower and upper bounds.

The case of non reinforced soil is first investigated. For this homogeneous problem, the Tresca criterion can be used directly, with no need for any approximation method. The numerical lower and upper bound values to the exact ultimate bearing capacity $Q_{n r}^{+}$are given at the top of Table 1 for different values of the loading inclination angle $\alpha$.

It appears that the relative gap between $Q_{n r}^{\mathrm{lb}}$ and $Q_{n r}^{\mathrm{ub}}$ vary from $6.3 \%$ to $19.6 \%$, depending on the inclination angle of the load. This gap is only due to the discretization of the structure into finite elements and the numerical optimization. It is worth noting that the exact value of $Q_{n r}^{+}$, which depend on 
the width of the strip footing $B$ and the undrained shear strength of the native soil $C_{s}$, are known for $\alpha=0^{\circ}$ and $\alpha=90^{\circ}[41]$ :

$$
Q_{n r}^{+}\left(0^{\circ}\right)=(\pi+2) B C_{s} \text { and } Q_{n r}^{+}\left(90^{\circ}\right)=B C_{s}
$$

These values are framed by the so-obtained numerical estimates and, for both values of $\alpha$, it seems that with the adopted discretization of the structure the static approach gives more accurate estimates than the kinematic approach.

Table 1: Lower and upper bounds estimate for the ultimate bearing capacity.

\begin{tabular}{|c|c|c|c|c|}
\hline$\alpha$ & $0^{\circ}$ & $30^{\circ}$ & $60^{\circ}$ & $90^{\circ}$ \\
\hline$Q_{n r}$ & 5.056 & 2.000 & 1.155 & 1.000 \\
\hline$\overline{B C_{s}}$ & 5.397 & 2.432 & 1.435 & 1.243 \\
\hline$Q_{c o l}$ & 11.631 & 2.000 & 1.111 & 0.856 \\
\hline$\overline{B C_{s}}$ & 14.341 & 2.434 & 1.285 & 0.982 \\
\hline $\bar{Q}$ & 13.477 & 2.182 & 0.938 & 0.720 \\
\hline$\overline{B C_{s}}$ & 15.548 & 3.008 & 1.335 & 0.998 \\
\hline
\end{tabular}

The ultimate bearing capacity of a stone column reinforced soil is then evaluated numerically by carrying out the previously described homogenization approach. The final lower and upper bound estimates, denoted by $Q_{c o l}^{\mathrm{lb}}$ and $Q_{c o l}^{\mathrm{ub}}$ respectively, are given in the middle of Table 1 . The relative gap between these two bounds ranges between $12.9 \%$ and $20.0 \%$. That proves that the whole numerical procedure proposed here, gives a reasonably good interval of confidence for the ultimate bearing capacity of a reinforced foundation. Concerning the calculation times, for a given $\alpha$, it takes 120 seconds for evaluating $Q_{\mathrm{col}}^{\mathrm{lb}}$ or $Q_{c o l}^{\mathrm{ub}}$, whereas the strength capacity of the non reinforced soil is estimated in less than 10 seconds.

The performance of the stone column reinforced soil can be compared to the non reinforced case, depending on the load inclination. Thus for a vertical load $\left(\alpha=0^{\circ}\right)$, the bearing capacity is multiplied by a factor equal to 2.30 for the lower bounds and 2.66 for the upper bounds. Furthermore the bearing capacity of the reinforced soil strongly decreases as the load is becoming horizontal. It should even be observed that for the extreme value of $\alpha=90^{\circ}$ (purely horizontal loading) the bearing capacity of the reinforced foundation becomes lower than that of non reinforced one by as much as $14 \%$ to $15 \%$.

The corresponding failure mechanism (that is the optimal velocity field of the kinematic approach) is also infuenced by the presence of reinforcing columns, as shown in Figure 11. For a purely vertical load, the velocity field obtained by the numerical kinematic approach is much similar to the classical Prandtl's mechanism in the case of non reinforced soil, whereas for the stone column reinforced soil, a more "shallow" mechanism is observed (see Figure 11(b)).

Geotechnical engineers often consider that stone column reinforced soils obey a simplied criterion corresponding to a Mohr-Coulomb criterion, the strength 


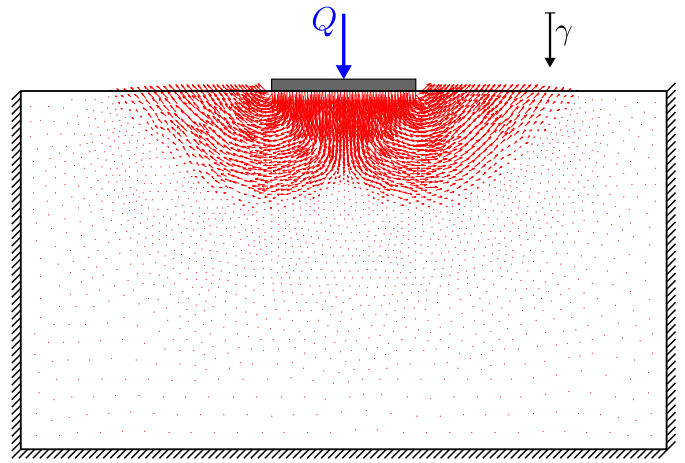

(a) Non reinforced soil

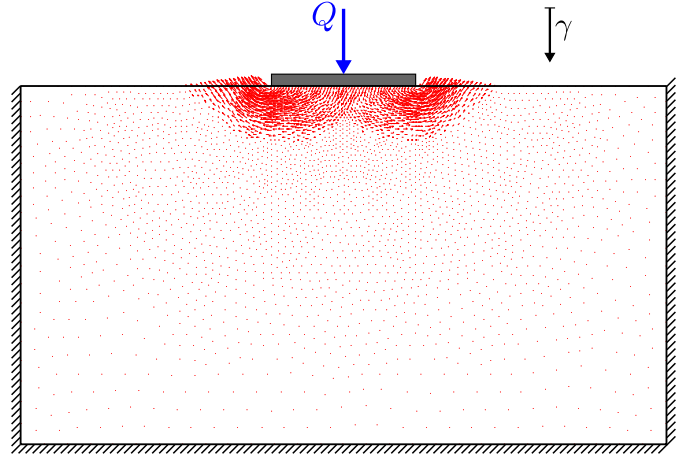

(b) Stone column reinforced soil

Figure 11: Failure mechanism obtained from the numerical optimization of the kinematic approach.

characteristics of which depend on the weighted average values of the strength properties of the soil and the stone column [18]. This average value may be calculated according to a rule of mixture formula in its simplest form, which gives, with the characteristics given in (11):

$$
\bar{C} / C_{s}=1-\eta=0.72 \text { and } \overline{\tan \varphi}=\eta \tan \varphi_{r}=0.196
$$

Again, the numerical static and kinematic approaches have been performed with such homogenized characteristics. These implementations do not involve any approximated domain. The so-obtained lower and upper bound estimates for the corresponding ultimate bearing capacity $\bar{Q}^{+}$are given in Table 1. For $\alpha=0^{\circ}$, the simplified criterion overestimates the bearing capacity of a stone column reinforced soil by a factor 1.1, while the result obtained with this simplified homogenized material is in quite good agreement with the homogenization-based result when the load is purely horizontal.

However, according to this "averaging" approximation, the reinforced soil is regarded as an isotropic material. But it has been shown in section 3 that this assumption is in strong contradiction with the numerical assessments of the macroscopic strength domain. Indeed, as shown in Figure 12, the relatively good agreement observed for the two extremal inclination angles, is no more verified when $\alpha$ varies for instance between $5^{\circ}$ and $30^{\circ}$, the averaging-isotropic approximation leading to significantly overestimate the ultimate bearing capacity.

\section{Conclusions}

In the present contribution a comprehensive yield design homogenization method has been proposed and fully implemented in order to evaluate numerically the strength properties of stone column reinforced soils. Lower and upper 


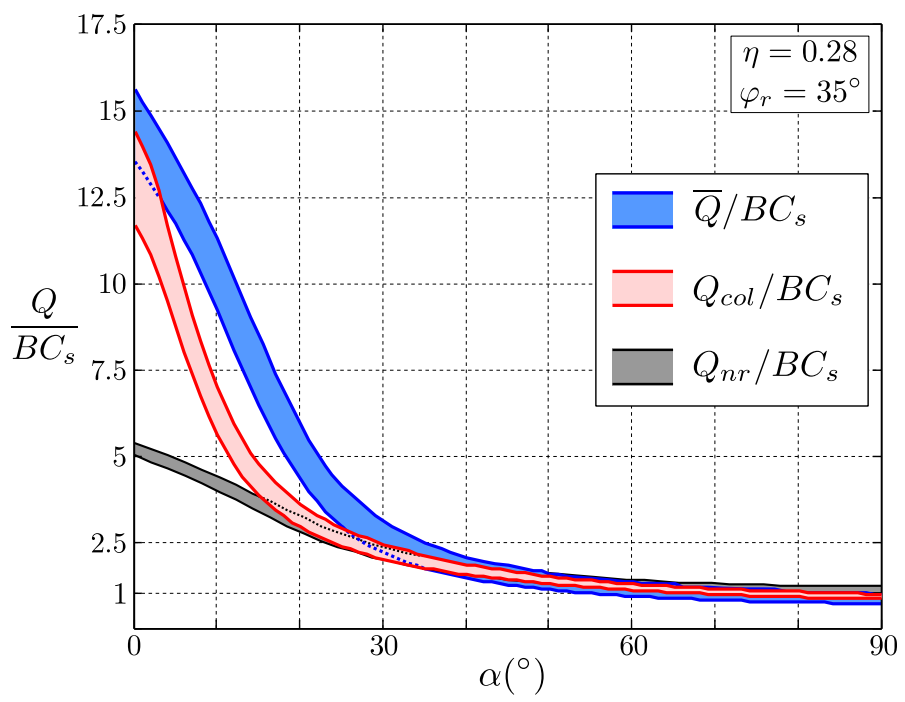

Figure 12: Ultimate bearing capacity estimates as functions of load inclination.

bound estimates for the macroscopic strength criterion of such a composite material have been produced from numerical optimization procedures. Since the direct use of these strength domains proves impossible for solving a structural problem, an existing approximation method of convex domains has been adapted to the case of unbounded domains.

The main advantage of this new approximation method is that it preserves a rigorous status for the so-obtained domains (lower bound or upper bound) and involves few parameters. Its performance in terms of accuracy has been proved, since for a given configuration of reinforced soil the relative gap between the two bounds remains smaller than $16 \%$. The implementation of the domains derived from this approximation method into a structural calculation involves optimization problems. The latter may be solved by using second-order cone programming, keeping a rigorous status of bounds to the final results.

The performance of the whole homogenization procedure is evaluated on a classical geotechnical problem. Following this procedure, lower and upper bound estimates for the bearing capacity of a stone column reinforced foundation are computed in less than two minutes each, whereas the calculation time may reach several hours at best when trying to solve the initial three-dimensional heterogeneous problem by using for instance a numerical elastoplastic procedure. Moreover, the proposed numerical method is accurate, since the relative gap between the two final bound estimates remains smaller than $20 \%$.

The ultimate bearing capacity of the stone column reinforced foundation has been compared to the non reinforced case. It appears that the reinforcing effect strongly depends on the load inclination, and can be even non existent in extreme cases (see Figure 12). Besides, it has been shown that the simplifying assumption according to which the strength properties of the reinforced soil 
could be modeled through averaged characteristics, may lead to significantly overestimate the actual anisotropic strength charactersitics of the reinforced soil and then the ultimate bearing capacity of a reinforced foundation. This suggests that a design of reinforced soil structures on the basis of such a crude simplifying assumption is not reliable, and that the actual anisotropic strength properties of the reinforced soil should absolutely be taken into account as it has been done here by means of a numerical implementation of the yield design homogenization method.

The feasability of the latter method and related numerical procedure has been demonstrated and illustrated on the typical example of a stone column reinforced foundation where new and original results have been obtained in the form of relatively close bounds on the ultimate bearing capacity. The accuracy of those bounds, and notably of the upper bound, could be further improved for example by making use, in the kinematic approach, of finite elements allowing for possible velocity jumps between them.

Finally, far from being restricted to particular reinforced soil structures, the proposed approach can be implemented on other kinds of problems, such as performing the stability analysis of embankments lying over reinforced soils, where bounds on the macroscopic strength criterion obtained in the present article can be readily applied [39].

\section{Appendix A. Details on the numerical approximation procedure}

It can be proved that the support function of the sum of $N$ ellipsoidal sets may be expressed by:

$$
\pi_{N \text { ell }}\left(\underline{\underline{D}}, \mathbb{A}_{k}, \underline{\underline{c}}\right)=\sum_{k=1}^{N} \sqrt{\underline{\underline{D}}: \mathbb{A}_{k}: \underline{\underline{D}}}+\underline{\underline{c}}: \underline{\underline{D}}
$$

where $\mathbb{A}_{k}$ is a fourth order tensor which specifies the orientation and the dimensions of the $k^{\text {th }}$ ellipsoid in the stress space and $\underline{\underline{c}}$ defines the center of one of the $N$ ellipsoids. Since the sum of convex ellipsoidal sets involves few parameters (if for instance $N \leq 15$ ), $6 N+3$ in the case of three-dimensional stress space, the obtained approximation is much easier to handle than the initial polyhedra, which involves several thousands of parameters.

An extension of this numerical procedure to unbounded strength domains is proposed here. First, the resolution of an optimization problem permits to obtain the characteristics of the ellipsoidal sets involved in the definition of $\mathbf{G}_{\mathrm{app}}^{\mathrm{lb}}$ and $\mathbf{G}_{\mathrm{app}}^{\mathrm{ub}}$. To approximate $\mathbf{G}^{\mathrm{lb}}$, the standard deviation of the difference between $\pi^{\mathrm{lb}}$ and the support function $\pi_{N \text { ell }}^{\mathrm{lb}}$, associated to $\mathbf{G}_{\mathrm{app}}^{\mathrm{lb}}$, is minimized along all the macroscopic strain rates in the cone $\{\underline{D}\}^{\mathrm{lb}}$, while the support function of the approximation must remain smaller than or equal to the support function 
of the numerical lower bound estimate for all strain rate directions of $\{\underline{\underline{D}}\}^{\text {lb }}$ :

$$
\begin{gathered}
\pi_{N \text { ell }}^{\mathrm{lb}}\left(\underline{\underline{D}}, \mathbb{A}_{k}, \underline{\underline{c}}\right)=\underset{\mathbb{A}_{k}, \underline{\underline{\underline{c}}}}{\operatorname{argmin}} \sum_{\underline{\underline{D}} \in\{\underline{\underline{D}}\}^{\mathrm{lb}}}\left(\pi^{\mathrm{lb}}(\underline{\underline{D}})-\pi_{N \mathrm{ell}}\left(\underline{\underline{D}}, \mathbb{A}_{k}, \underline{\underline{c}}\right)\right)^{2} \\
\text { subject to } \pi^{\mathrm{lb}}(\underline{\underline{D}}) \geq \pi_{N \mathrm{ell}}\left(\underline{\underline{D}}, \mathbb{A}_{k}, \underline{\underline{c}}\right), \quad \forall \underline{\underline{D}} \in\{\underline{\underline{D}}\}^{\mathrm{lb}}
\end{gathered}
$$

The characteristics of the ellipsoidal sets defining $\mathbf{G}_{\mathrm{app}}^{\mathrm{ub}}$ are obtained by solving the same kind of minimization problem, except that the associated support function $\pi_{N \text { ell }}^{\mathrm{ub}}$ has to be greater than or equal to $\pi^{\mathrm{ub}}$ for all strain rate directions of $\{\underline{\underline{D}}\}^{\mathrm{ub}}$ :

$$
\begin{gathered}
\pi_{N \text { ell }}^{\mathrm{ub}}\left(\underline{\underline{D}}, \mathbb{A}_{k}, \underline{\underline{c}}\right)=\underset{\mathbb{A}_{k}, \underline{\underline{c}}}{\operatorname{argmin}} \sum_{\underline{\underline{D}} \in\{\underline{\underline{D}}\}^{\mathrm{ub}}}\left(\pi^{\mathrm{ub}}(\underline{\underline{D}})-\pi_{N \text { ell }}\left(\underline{\underline{D}}, \mathbb{A}_{k}, \underline{\underline{c}}\right)\right)^{2} \\
\text { subject to } \pi^{\mathrm{ub}}(\underline{\underline{D}}) \leq \pi_{N \text { ell }}\left(\underline{\underline{D}}, \mathbb{A}_{k}, \underline{\underline{c}}\right), \quad \forall \underline{\underline{D}} \in\{\underline{\underline{D}}\}^{\mathrm{ub}}
\end{gathered}
$$

Moreover, for all strain rates $\underline{\underline{D}}$ not belonging to the relevance cone of the numerical bound estimate, the support function defining the approximated domain must be infinite. As $\pi^{\mathrm{lb}}$ or $\pi^{\mathrm{ub}}$, the numerical sets $\{\underline{\underline{D}}\}^{\mathrm{lb}}$ and $\{\underline{\underline{D}}\}^{\mathrm{ub}}$ are complex to handle in the upcoming implementation of the discretized homogenized equivalent problem. Thus, it has been decided to express an approximation to each set as a conic condition of the form:

$$
\underline{\underline{D}} \in\{\underline{\underline{D}}\}_{\mathrm{app}} \Leftrightarrow \alpha_{1} D_{11}+\alpha_{2} D_{22} \geq \alpha_{3} \sqrt{\alpha_{4}^{2}\left(D_{11}-D_{22}\right)^{2}+\alpha_{5}\left(2 D_{12}\right)^{2}}
$$

where the $\alpha_{i}$ are parameters obtained from an optimization procedure. It is to be noticed that this condition corresponds to the relevance condition of the Mohr-Coulomb criterion if $\alpha_{1}=\alpha_{2}=\alpha_{4}=\alpha_{5}=1$ and $\alpha_{3}=\sin \varphi$. In order to keep a rigorous bound status for both approximated domains the following conditions must be respected during the optimization procedure:

$$
\begin{aligned}
& \{\underline{\underline{D}}\}^{\mathrm{lb}} \subseteq\{\underline{\underline{D}}\}_{\mathrm{app}}^{\mathrm{lb}} \\
& \{\underline{\underline{D}}\}_{\mathrm{app}}^{\mathrm{ub}} \subseteq\{\underline{\underline{D}}\}^{\mathrm{ub}}
\end{aligned}
$$

Finally, each approximated criterion $\mathbf{G}_{\text {app }}$ is defined by its support function $\pi_{\text {app }}$, depending on its cone of outer normals $\{\underline{\underline{D}}\}_{\text {app }}$, as follows

$$
\mathbf{G}_{\mathrm{app}}=\bigcap_{\underline{\underline{D}}}\left\{\underline{\underline{\underline{\Sigma}}} \mid \underline{\underline{\underline{\Sigma}}}: \underline{\underline{D}} \leq \pi_{\mathrm{app}}(\underline{\underline{D}})\right\}
$$

where

$$
\pi_{\text {app }}(\underline{\underline{D}})= \begin{cases}\pi_{N \text { ell }}\left(\underline{\underline{D}}, \mathbb{A}_{k}, \underline{\underline{c}}\right) & \text { if } \underline{\underline{D}} \in\{\underline{\underline{D}}\}_{\text {app }}\left(\alpha_{i}\right) \\ +\infty & \text { otherwise }\end{cases}
$$

The parameters $\alpha_{i}$ and components of $\mathbb{A}_{k}$ and $\underline{\underline{c}}$ are related to the numerical macroscopic strength domain which is approximated. 


\section{References}

[1] J. Salençon, Calcul à la rupture et analyse limite, Presses de l'Ecole Nationale des Ponts et Chaussées, 1983.

[2] J. Salençon, Yield design, ISTE-Wiley, Hoboken, NJ USA, 2013.

[3] D. C. Drucker, W. Prager, Soil mechanics and plastic analysis or limit design, Quarterly of Applied Mathematics 10 (2) (1952) 157-165.

[4] A. H. Soubra, Upper-bound solutions for bearing capacity of foundations, Journal of Geotechnical and Geoenvironmental Engineering 125 (1) (1999) $59-68$.

[5] R. L. Michalowski, Stability assessment of slopes with cracks using limit analysis, Canadian Geotechnical Journal 50 (10) (2013) 1011-1021.

[6] J. Lysmer, Limit analysis of plane problems in soil mechanics, Journal of the Soil Mechanics and Foundations 96 (1970) 1311-1334.

[7] J. Pastor, S. Turgeman, Mise en œuvre numérique des méthodes de l'analyse limite pour les matériaux de von mises et de coulomb standards en déformation plane, Mechanics Research Communications 3 (6) (1976) 469-474.

[8] M. Trillat, J. Pastor, Limit analysis and gurson's model, European Journal of Mechanics-A/Solids 24 (5) (2005) 800-819.

[9] M. Trillat, J. Pastor, P. Francescato, Yield criterion for porous media with spherical voids, Mechanics Research Communications 33 (3) (2006) 320328.

[10] K. Krabbenhøft, A. V. Lyamin, S. W. Sloan, Three-dimensional mohrcoulomb limit analysis using semidefinite programming, Communications in Numerical Methods in Engineering 24 (11) (2008) 1107-1119.

[11] A. J. Li, R. S. Merifield, A. V. Lyamin, Limit analysis solutions for three dimensional undrained slopes, Computers and Geotechnics 36 (8) (2009) $1330-1351$.

[12] S. W. Sloan, Geotechnical stability analysis, Géotechnique 63 (7) (2013) $531-572$.

[13] K. M. Kouzer, J. Kumar, Vertical uplift capacity of two interfering horizontal anchors in sand using an upper bound limit analysis, Computers and Geotechnics 36 (6) (2009) 1084-1089.

[14] S. D. Clarke, C. C. Smith, M. Gilbert, Modelling discrete soil reinforcement in numerical limit analysis, Canadian Geotechnical Journal 50 (7) (2013) $705-715$. 
[15] J. Kumar, J. P. Sahoo, Bearing capacity of strip foundations reinforced with geogrid sheets by using upper bound finite-element limit analysis, International Journal for Numerical and Analytical Methods in Geomechanics 37 (18) (2013) 3258-3277.

[16] J. J. Muñoz, A. V. Lyamin, A. Huerta, Stability of anchored sheet wall in cohesive-frictional soils by fe limit analysis, International Journal for Numerical and Analytical Methods in Geomechanics 37 (9) (2013) 12131230.

[17] B. Broms, Lime and lime/columns. summary and visions, in: Proceedings of the 4 th International Conference on Ground Improvement Geosystems: Keynotes Lecture, Helsinky, 2000, pp. 43-93.

[18] H. J. Priebe, The design of vibro replacement, Ground Engineering 28 (10) (1995) 31-37.

[19] P. de Buhan, A fundamental approach to the yield design of reinforced soil structures (in french), Thèse d'Etat, paris VI (1986).

[20] G. Hassen, M. Gueguin, P. de Buhan, A homogenization approach for assessing the yield strength properties of stone column reinforced soils, European Journal of Mechanics-A/Solids 37 (2013) 266-280.

[21] P. Suquet, Elements of homogenization for inelastic solid mechanics, no. 272 in Lecture Notes in Physics, Springer-Verlag, Berlin, 1987, Ch. Homogenization techniques for composite, pp. 193-278.

[22] P. de Buhan, R. Mangiavacchi, R. Nova, G. Pellegrini, J. Salençon, Yield design of reinforced earth walls by a homogenization method, Géotechnique 39 (2) (1989) 189-201.

[23] P. de Buhan, A. Taliercio, A homogenization approach to the yield strength of composite materials, European Journal of Mechanics-A/Solids 10 (2) (1991) 129-154.

[24] A. Sawicki, D. Lesniewska, Limit analysis of cohesive slopes reinforced with geotextiles, Computers and Geotechnics 7 (1) (1989) 53-66.

[25] R. Abdi, P. de Buhan, J. Pastor, Calculation of the critical height of a homogenized reinforced soil wall: a numerical approach, International Journal for Numerical and Analytical Methods in Geomechanics 18 (7) (1994) 485505 .

[26] R. Michalowski, A. Zhao, Continuum versus structural approach to stability of reinforced soil, Journal of Geotechnical Engineering 121 (2) (1995) 152162 . 
[27] B. Jellali, M. Bouassida, P. de Buhan, A homogenization method for estimating the bearing capacity of soils reinforced by columns, International Journal for Numerical and Analytical Methods in Geomechanics 29 (10) (2005) 989-1004.

[28] P. Francescato, J. Pastor, Lower and upper numerical bounds to the offaxis strength of unidirectional fiber-reinforced composites by limit analysis methods, European Journal of Mechanics-A/Solids 16 (2) (1997) 213-234.

[29] H. X. Li, Y. Liu, X. Feng, Z. Cen, Limit analysis of ductile composites based on homogenization theory, Proceedings of the Royal Society of London. Series A: Mathematical, Physical and Engineering Sciences 459 (2031) (2003) 659-675.

[30] H. X. Li, Limit analysis of composite materials with anisotropic microstructures: A homogenization approach, Mechanics of Materials 43 (10) (2011) $574-585$.

[31] B. Jellali, M. Bouassida, P. de Buhan, Stability analysis of an embankment resting upon a column-reinforced soil, International Journal for Numerical and Analytical Methods in Geomechanics 35 (11) (2011) 1243-1256.

[32] M. Gueguin, G. Hassen, P. de Buhan, Ultimate bearing capacity of a foundation reinforced by columns or cross trenches under inclined loads: homogenization approach, International Journal for Numerical and Analytical Methods in Geomechanics (2014) DOI:10.1002/nag.2307.

[33] B. Jellali, M. Bouassida, P. de Buhan, A homogenization approach to estimate the ultimate bearing capacity of a stone column reinforced foundation, International Journal of Geotechnical Engineering 1 (9) (2007) 61-69.

[34] M. Gueguin, G. Hassen, P. de Buhan, Numerical assessment of the macroscopic strength criterion of reinforced soils using semidefinite programming, International Journal for Numerical Methods in Engineering 99 (7) (2014) $522-541$.

[35] G. Hassen, P. de Buhan, M. Abdelkrim, Finite element implementation of a homogenized constitutive law for stone column-reinforced foundation soils, with application to the design of structures, Computers and Geotechnics 37 (1) (2010) 40-49.

[36] J. Bleyer, P. de Buhan, Yield surface approximation for lower and upper bound yield design of $3 \mathrm{~d}$ composite frame structures, Computers and Structures 129 (2013) 86-98.

[37] A. Makrodimopoulos, C. M. Martin, Lower bound limit analysis of cohesive-frictional materials using second-order cone programming, International Journal for Numerical Methods in Engineering 66 (4) (2006) 604634 . 
[38] A. Makrodimopoulos, C. M. Martin, Upper bound limit analysis using simplex strain elements and second-order cone programming, International Journal for Numerical and Analytical Methods in Geomechanics 31 (6) (2007) 835-865.

[39] M. Gueguin, A homogenization approach for assessing the behavior of reinforced soils by columns or trenches (in french), Ph.D. thesis, Université Paris-Est, available from: http://hal.archives-ouvertes.fr/tel-01057009/ [October 2014] (2014).

[40] MOSEK, The mosek optimization software, available from: http://www. mosek. com [August 2014].

[41] J. Salençon, A. Pecker, Ultimate bearing capacity of shallow foundations under inclined and eccentric loads. part i: Purely cohesive soil, European Journal of Mechanics-A/Solids 14 (3) (1995) 349-375. 